\title{
LITERACY AND LANGUAGE TEACHING: TOOLS, IMPLEMENTATION AND IMPACT ${ }^{1}$
}

\author{
Fernanda Minuz $2^{2}$, Alessandro Borri ${ }^{3}$
}

\section{SYLLABUS AND DESCRIPTORS FOR ILLITERATE, SEMI-LITERATE AND LITERATE USERS. FROM ILLITERACY TO A1 LEVEL}

Although the first courses of Italian Language for adult migrants date back to the 80 's, the need for new tools for course planning and test design has recently increased, mainly due to several factors, which are grossly common in Europe, albeit with national differences.

Firstly, the growth of the migrant population - nowadays representing $8,2 \%$ of the Italian population - has diversified the educational needs, including language needs, according to the different biographies, projects, individual paths of access to the host society, actual living situations, cultural and linguistic backgrounds. Secondly, the recent influx of asylum seekers and refugees requires a fast adaptation of the language provision to new teaching environments, such as short courses - due to the mobility of the asylum seekers/refugees population -, focused on the first linguistic support, and meanwhile preparing the refugees for further vocational training and job search.

As the language legal requirements - the certification of level A2 and KoS - have pushed a larger part of the migrants to attend language courses, the significant presence of illiterates and persons with learning difficulties has emerged. Language courses and manuals for L2 teaching to illiterates have been offered since the 80s, with a rather irregular trend (Minuz, 2005), but the awareness of the need for specific approaches and teaching methodologies were largely confined to teachers and few researchers. The topics of literacy and language teaching has come to a foreground at the turn of century and it has become a specialised area of the Language Teaching.

Finally, the language courses are greatly heterogeneous, in terms of providers, teaching quality, and standardised procedures to assess the language needs of the learners. In Italy, providers are public (mostly the state Adult Education Centres), NGOs and humanitarian agencies, private (mostly vocational training centres). The language teachers' competence ranges from highly professionalized to not-specific, with no relation to the type of provider. Some language course providers adopt procedures to define the learners' profiles, their needs and to set up tailor-made courses; others do not.

\footnotetext{
${ }^{1}$ Una sintesi di questo articolo sarà pubblicata in Beacco J-C., Little, D., Krumm H-J. and Thalgott Ph. (eds.) (2017), The Linguistic Integration of Adult Migrants: Some Lessons from Research. Berlin: De Gruyter Mouton in cooperation with the Council of Europe.

${ }^{2}$ Già Johns Hopkins - SAIS Europe.

${ }^{3}$ CPIA Montagna, Castel di Casio (Bo).
} 
Italiano lingua seconda in contesti migratori. Sillabo e descrittori dall'alfabetizzazione all'A1 (IL2S) (Borri, Minuz, Rocca, Sola, 2014) is a tool to plan courses, to create teaching materials and to prepare diagnostic and achievement tests at levels preceding the level A1 of the Common European Framework, to which is explicitly related. It endorses the CEFR approach, especially the notion of communicative language competence as a multidimensional competence and a part of a more general action competence. The individual is considered a social agent and is primarily described according to language performance on specific themes, with specific tasks and in specific domains.

The need to identify descriptors of language proficiency for first levels in migration contexts, specifically, for levels that are lower than those of the Common European Framework (Council of Europe, 2001), has become more and more apparent, in relation to the daily situations in many member states of the Council of Europe. Syllabuses for different national languages have been issued (Beacco, De Ferrari, Lhote, Tagliante, 2005; BMF, 2009; Fritz, Faistauer, Ritter, Hribesch, 2006; Beroepsoderwijs en volwasseneneducatie, 2008; Rocca, 2009; Finnish National Board, 2012; Markov, Scheithauer, Schramm, 2015). We have taken them into account in writing Italiano lingua seconda, as well as the development of CEFR promoted by the Council of Europe.

IL $2 S$ consists of four parts. The Syllabus defines the domains and the thematic areas. The first section of the Descriptors (Tables A) presents the levels of language competence and literacy in terms of "can do", coherently with the approach of CEFR: that is the actions which a learner should be able to perform in four domains (private, public, professional, educational) and about six main topics. The second section (Tables B) lists the language contents that a learner should know to perform those actions. They are based on the Italian output of the European project "Reference Level Descriptions" (Spinelli, Parizzi, 2010), with the needed integrations and modifications.

The third section (Table C) presents the "Literacy goals" and is divided in "Technical skills" and "Study skills". A "Word list" completes the lexical area.

As we consider literacy as a part of the broader communicative language competence, the Literacy objectives are strongly linked to the preceding sections.

Table. 1.

\begin{tabular}{|c|c|c|c|c|c|c|c|}
\hline \multirow{3}{*}{$\frac{n}{\frac{a}{b}}$} & \multicolumn{6}{|c|}{ Thematic Areas } & \multirow{3}{*}{ Macro sections } \\
\hline & $\begin{array}{l}\text { Personal } \\
\text { domain }\end{array}$ & \multicolumn{2}{|c|}{$\begin{array}{l}\text { Public } \\
\text { domain }\end{array}$} & \multirow{2}{*}{$\begin{array}{c}\begin{array}{c}\text { Occupational } \\
\text { domain }\end{array} \\
5\end{array}$} & \multicolumn{2}{|c|}{$\begin{array}{c}\text { Educational } \\
\text { domain }\end{array}$} & \\
\hline & 1 & 3 & 4 & & & 6 & \\
\hline \multirow{12}{*}{ 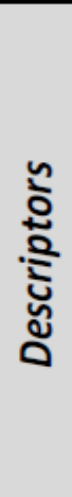 } & \multicolumn{6}{|c|}{ TTA } & \multirow{2}{*}{ Progression } \\
\hline & TSA.1 & TSA.2 & TSA.3 & TSA.4 & TSA.5 & TSA.6 & \\
\hline & \multicolumn{6}{|c|}{ тाв1 } & Function \\
\hline & \multicolumn{6}{|c|}{ TाB2 } & General notions \\
\hline & \multicolumn{6}{|c|}{ TTB3 } & Specific notions \\
\hline & TSB3.1 & TSB3.2 & TSB3.3 & TSB3.4 & TSB3.5 & TSB3.6 & \\
\hline & \multicolumn{6}{|c|}{ TाB4 } & Textual genres \\
\hline & TSB4.1 & TSB4.2 & TSBA. & \begin{tabular}{|l|l|}
3 & TSB4.4 \\
\end{tabular} & TSB4.5 & TSB4.6 & \\
\hline & \multicolumn{6}{|c|}{ TTB5 } & Grammar \\
\hline & \multicolumn{6}{|c|}{ тाв6 } & $\begin{array}{l}\text { Phonetics and } \\
\text { orthography }\end{array}$ \\
\hline & \multicolumn{6}{|c|}{ तTC } & Literacy goals \\
\hline & \multicolumn{6}{|c|}{ Word list } & Lexical goals \\
\hline
\end{tabular}


IL $2 S$ foresees four stages: the fourth corresponds to the level A1 of the CEFR, and the previous three describe learning objectives for three different users: pre-literate, illiterate and semi-literate.

Table 2.

\begin{tabular}{|c|c|c|c|c|c|}
\hline Stage & Pre alpha A1 & Alpha A1 & Pre A1 & & A1 \\
\hline Users & $\begin{array}{l}\text { Pre---literate } \\
\text { and/or illiterate } \\
\text { "slow learners" }\end{array}$ & Illiterate & Semi---Lit & rate & Literate \\
\hline Program & $\begin{array}{l}\text { Orientation } \\
\text { and } \\
\text { Pre-literacy }\end{array}$ & $\begin{array}{l}\text { Orientation and } \\
\text { Literacy }\end{array}$ & $\begin{array}{l}\text { Close } \\
\text { CEFR }\end{array}$ & & CEFR \\
\hline Learning Hours & 100 & 250 & 150 & & 100 \\
\hline \multirow{4}{*}{ Progress } & \multicolumn{5}{|c|}{ READING AND WRITING } \\
\hline & Recognizing & Succeeding & \multicolumn{2}{|c|}{$\begin{array}{l}\text { Beginning to } \\
\text { know how }\end{array}$} & Knowing how \\
\hline & \multicolumn{5}{|c|}{ ORAL INTERACTION } \\
\hline & Succeeding & \multicolumn{2}{|c|}{$\begin{array}{l}\text { Beginning to know } \\
\text { how }\end{array}$} & \multicolumn{2}{|c|}{$\begin{array}{l}\text { Knowing how (first } \\
\text { and second phase }\end{array}$} \\
\hline
\end{tabular}

\section{ASSESSMENT OF ITALIANO LINGUA SECONDA. SILLABO E DESCRITTORI}

\subsection{Scope and methodology}

A validation procedure was set up, in order to assess accuracy, validity and impact of IL2S. With the term "accuracy", we intend its descriptive power: can it guide the users in identifying levels of competence in language learning and literacy with an acceptable degree of precision and discriminatory power? "Validity" means here its appropriateness to the end: is IL2S useful, and user-friendly? Is it useful in setting realistic learning objectives? The third goal of the trial was to assess the impact on the quality of the language courses and testing: did IL2S affect approaches to language teaching, course planning, and test design? 
The trial focused on the development of writing ability, starting from instrumental and functional literacy.

\subsection{Methodology}

We carried out the validation procedure in two phases: during the spring semester 2014, as the piloting phase of the IL2S draft, and the school year 2015-2016, as the validating phase.

\subsubsection{Sampling of the participants}

We selected the educational agencies participating in the assessment taking into account the diversity of the language teaching provision. Out from the ten educational agencies involved, 5 are State Adult Education Centre (CPIA), 4 are voluntary associations/NGOs, 1 is a vocational training agency. They are based in 10 towns, in Northern, Central and Southern Italy. 19 teachers have participated on a voluntary basis, after a short training ${ }^{4}$.

\subsubsection{Overview of the teaching situations}

Due to diversity in the language course provision and among the learners, we have carried out a preliminary overview of the targeted language centres, focusing on courses A1 and below.

The teachers were asked to fill in two types of questionnaires.

The first aims at identifying the research participants' profiles and the compositions of the classes. The questionnaire gathers data on the teachers' educational backgrounds and experiences in L2 teaching, number of classes taught, composition of the classes according to countries of origin, L1s, L2s, levels of literacy of the students, organization of the lessons. The research participants were invited to point out the main critical aspects of the teaching and add relevant comments.

The second questionnaire, to be filled in for each student by the research participants, is aimed to define the learners' profiles: information on the linguistic repertoires of the learners, literacy, and quantity of contacts with Italian speakers is asked.

\footnotetext{
${ }^{4}$ We thank the research participants: Assunta Barletta (CTP Castiglione dei Pepoli); Laura Carolina Grugni (CTP Castel San Giovanni); Lucia Mazzoli (CTP Senigallia); Maria Immacolata Giannuzzi, Luisa Rizzo, Ivan Serra (CPIA Lecce); Natalizia Totaro (CPIA Treviso); Monica Francioso (Società Cooperativa Sociale Pro Alter 2000, Melicuccà); Bianca Balatresi, Valeria Boccia, Florinda D'Amico, Antonella Giangiacomo (Focus Casa dei diritti, Roma); Milena Angius, Sara Brattoli, Marco Musso (Istituto Beata Vergine dell'Addolorata, Milano); Simona Di Rubba, Roberto Mancini (Cieli aperti, Prato); Francesca Marchi, Francesca Patuelli (CEFAL, Bologna).
} 


\subsubsection{Collection and analysis of samples of learners' written productions}

In order to assess the accuracy and validity of IL2S as a tool to describe levels of communicative language competence and literacy and to set learning objectives, we tested the descriptors on samples of writing produced by the students, focusing on the new proposed levels Pre-Alpha, Alpha A1, Pre-A1.

We asked teachers to gather samples of written productions (sheets of paper and copies of exercise books) in three different stages: in the first 5 hours; between the $20^{\text {th }}$ and the $25^{\text {th }}$ hour of the course; between the $50^{\text {th }}$ and $55^{\text {th }}$ hour of the course and/or at the end of the course. The study produced a corpus of more than 800 pages of exercise books. Some teachers collected also audio/video records of oral productions.

\subsubsection{Feedback from the research participants}

In order to assess the validity of IL $2 S$ and its impact on the teaching practices, we gave the research participants the instruction to experiment IL2S by integrating it into their everyday practices. At the end of the trial, we asked for feedback through structured-interviews. The interviews have elicited information on the actual uses of IL $2 S$, comments about its impact on course planning and quality, as well as on its validity. This information complements the data collected through the first questionnaire.

\section{RESULTS}

\subsection{Teaching setting, classes, and teachers}

The research participants used IL2S to plan and implement 14 courses: 2 AlphaA1/preA1; 10 A1 with literate and illiterate participants; 2 multilevel level classes. The average duration of the courses was 60 hours, from a minimum of 30 to a maximum of 100 hours.

167 students attended the course, 104 men and 63 women, from 18 countries, and with 19 mother tongues. 48 of them claimed to be able to speak at least one Second language (11 L2 other than Italian).

The research confirmed well-known problems. All classes were highly diverse in terms of the language competence, literacy, and linguistic backgrounds of the students, in some cases ranging from illiterates without any knowledge of Italian to A2 educated students. Moreover, individual students rarely presented homogeneous profiles: some students who were pre-A1 in writing skills could speak Italian up to B1. Thus, teachers, all of them with relevant experience or education, claimed to use differentiated teaching techniques, mostly based on cooperative learning approaches.

The main difficulty that I met (in piloting IL2S) is organizational, as the illiterate students who have participated in the research are part of a broader A1 class. Thus, I had to organize the lessons so that all students could advantageously work, according to their needs and their demands. 
A second common critical issue was irregular course attendance: this was the case, even when learners showed strong interest and motivation to language learning. Teachers mentioned difficult conciliation between study and everyday life as the cause for irregular frequency of women, while mobility appeared to be the main cause for asylum seekers. The majority of teachers commented that the class ambiance was pleasant, cooperative and motivating, apart from one: the class was composed of 23 students of 7 different nationalities and mother tongues, all of them low educated, including one illiterate, with an oral competence ranging from pre-Alfa to B1. However, illiterates could show "distress", "discouragement", "confusion", reported in two cases. In particular, one teacher regretted that the class had split between the more and less competent students, because of the pressure to obtain the legal language test: «this has created a sort of 'silent minority' composed of the low educated students, while the students with competences much higher than others have come into the foreground».

In the second phase of the research, the teachers commented the changes prompted by the flows of refugees and asylum seekers, which have increased dramatically since 2014. Even in the well-established language teaching agencies (both public or NGOs) such as those targeted by the research - the need for a quick response to the sudden and irregular presence of refugees and asylum seekers in a given area has affected the size and the configuration of the classes, as well as the organization of the teaching activities. Classes sometimes are overcrowded (up to 40 students); course can be too short (30 hours for language teaching and literacy); extra rooms can be inadequate. The teaching setting becomes a hindering factor: one teacher complained that short duration and inadequate location of the course limited the class activities, which she usually carries out in her Adult Education Centre.

\subsection{Accuracy and validity}

The research results confirmed at large the accuracy of IL $2 S$ as descriptive and assessment tool and its validity in representing the development of communicative language skills and literacy. Some problems with specific descriptors and the layout were pointed out:

it has been useful for identifying the learners' profiles and for preparing the teaching materials. I am speaking of the teaching materials as the syllabus, which is now at our disposal, presented good guidelines to "keep a progression". Sometimes, when you write teaching materials, you get lost. Staying vigilant and having the syllabus as a basis allowed for more focused work.

\subsubsection{Learning objectives}

We tested the descriptors on samples of writing produced by the students, as in the following example (Figure 1). It was produced as a response to the task "Write a shopping list", which the class had practised several times; the student wrote the words without assistance. 
Figure 1.

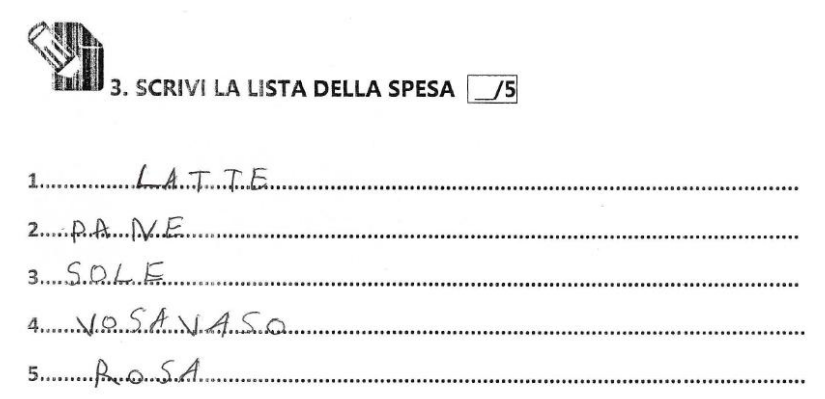

The sample corresponds to Alpha A1 descriptors such as: $\mathrm{He} /$ she understands the relation between the spoken and written language; $\mathrm{He} /$ she can write single words, which are of personal interest or familiar (capital script). The student has understood the alphabetic principle (correspondence between phonemes and graphemes), although with some uncertainty in combining sounds and letters (vosa vaso - vaso). However, she produces a list made up of incongruous words (milk, bread, sun, vase, rose), confirming that the ability to write a simple text as a shopping list pertains to the level Pre-A1.

The student appears to focus on showing her ability to write the words that she has practised in the literacy exercises (bi-syllables, paroxytone words). However, the ability to implement reality-oriented tasks requires that learners understand the aims, formats, and conventions of the learning activities. This understanding is a result of schooling and is stated as a literacy objective in IL2S at the level Alpha A1: He/she starts to recognize the types of exercises and teaching activities.

The example below (Figure 2) is the result of a teaching unity on food, which took place after 50 hours of instruction and involved students in several activities - such as speaking, copying, sentence and word segmentation - through different techniques. The photo shows a previous exercise aimed at developing phonological awareness, above the sentence.

The student, a Malian young man without previous schooling, wrote the sentence with strong guidance by the teacher and the aid of syllabic tables, cards and words written on the blackboard. Among the relevant objectives stated by IL2S we quote: $\mathrm{He} /$ she understands the alphabetic principle (correspondence between graphemes and phonemes); $\mathrm{He} /$ she understands the notion of word and starts to understand the idea of sentence; If supported, he/she starts to write very short familiar sentences.

Figure 2.

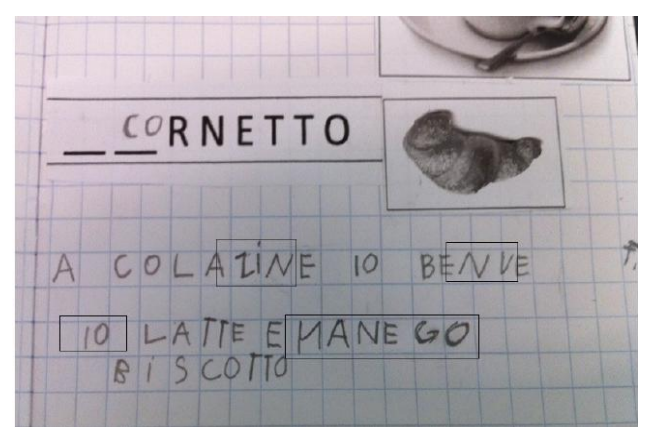


The student starts to write single familiar, well-trained words correctly (latte/milk, biscotto/cake, io/I), and he is able to reproduce familiar phrases with a degree of accuracy (a colazine - a colazione/at breakfast). He seems to have understood the representational nature of written language, but some areas are still in a developing stage. The attribution of a given phoneme to the correspondent grapheme is sometimes incorrect. In benvebeve (he drinks), the students seems more focused on the graphic form of the word than in the representation of the sounds. In manego - mangio (I eat), the complex syllables combination is normalized in three syllables $\mathrm{CV}$, the most common type in the Italian language and the first to be taught. In both cases, one can assume difficulties in the segmentation of words into phonemes and phonemic groups, probably due to a difficulty to treat the new phonetic system. The delimitation of the words (io latteemanego) seems uncertain. As far as the language competence is concerned, the sentence shows that the system of verbs (benve - bevo), as well as the noun syntagma (biscotto - un biscotto, biscotti) are not completely acquired. The incorrect repetition of the pronoun io is due probably to the focus on the good reproduction of the sentence, in terms writing conventions.

\subsubsection{Open questions}

All research participants remarked that IL $2 S$ was valuable in outlining the profiles of students, thus in better designing tailor-made courses. It has sharpened their diagnostic skills, they remarked, drawing their attention to aspects less in foreground in the standard entry assessment tools, such as the main domains in which learners habitually use the Italian language or their multilingual repertoires.

However, one research participant has pointed out problems in dealing with the PreAlpha level, as she has found incongruences between the profile Pre-Alpha as described in the Guidelines and the descriptors of the level Alpha-A1:

When I read the Tables, I would place students such as F. at the level PreA., although he speaks French [as L2], has the notion of written language and its relevance. I placed him at the level Pre-Alpha at the beginning of the course, because when he arrived he spoke only French, he knew some correspondences between graphemes and phonemes (two or three) - which he pronounced approximately. Yet, he was not able to put together two letters and he did not find his way.

We must remark that the descriptors refer to the exit competence, at the end of the course. F. presents the typical profile of illiterate Alpha A1 learners at the beginning of the course. However, the research participant brings to light the twofold function of the stages identified before A1. On the one hand, they are designed in relation to specific groups of learners: Pre-Alpha A1 descriptors state the probable performances of preliterate or slow learners after 100 hours of instruction. In this sense, the stages do not prefigure a progression for all students, as illustrated in the chart-flow (Figure 3). However, the two literacy stages Pre-Alpha and Alpha A1 (and to a lesser extent for Pre-A1), can represent levels, that is steps toward the acquisition of literacy. Further classroom research is needed. 
Figure 3.

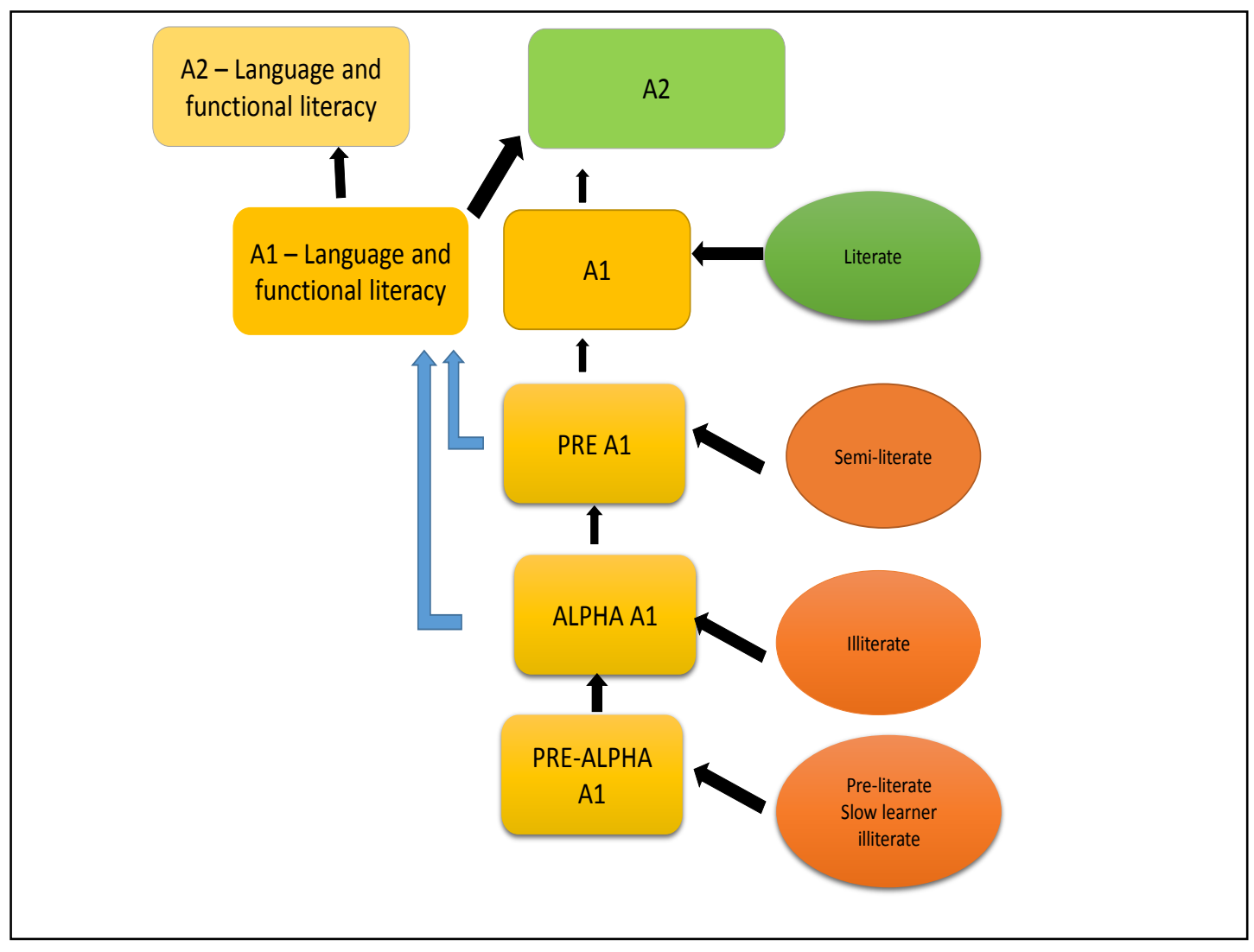

Generally, the stress on different forms of illiteracy, in the continuum between illiterates and strong literates, was appreciated.

The notion of levels per se was questioned:

When we began to leaf through the Syllabus, all of us realized that you go in and out the levels. A level alone does not exist, but there are different levels for the different skills.

We propose to consider the levels not as unitary profiles, but as indicators of competence that must be re-assembled case by case (Beacco, 2008; Minuz, Borri, Rocca, 2016).

The heterogeneous individual profiles appear particularly crucial with illiterate learners, and raise the question of the relation between development of oral ability and literacy.

IL $2 S$ assumes that the incoming learner is at a minimum level of oral ability or is not able at all; therefore, it defines sequences of language contents that proceed in parallel in terms of written and oral abilities. However, the relationship between oral abilities and level of education, for adult illiterates in particular, is not yet fully understood. If one considers the connection between these two competences in L2 guided learning, the 
experience emphasizes that illiterate subjects most likely need longer time to learn oral language, than semi-literate or literate subjects. The practical data are confirmed by psycholinguistic research, although still at an early stage: illiteracy seems to be related to a lower ability to be aware of and to process linguistic forms (i.e. phonemes, morphemes, words), which influences the development of oral language (Tarone, Bigelow, 2005). Moreover, illiterate people and people with low literacy skills cannot access the variety of texts and uses of language that reading and writing allow; the language input is less rich and varied.

Some of the participants reported to be more attentive than in the past to the different rates of acquisition of spoken language and literacy, as well as of reading and writing.

I also have given more attention to spoken language. My approach was to focus on reading and writing, I tended to leave out the oral skills, but now I have balanced my approach more.

\subsection{Impact on teaching practices}

Concerning the actual use of IL2S, most participants reported that they utilized IL2S to define learners' profiles - as a step in the needs analysis procedure -, design courses, and write teaching materials.

The research participants stated to use all sections of IL $2 S$, including the Guidelines, in setting the course objectives. However, they affirmed that they did not «followed them slavishly»; on the contrary, they made changes, when necessary. For example, the suggested themes, which are relevant for the most migrants (like job, housing, services) proved to be inappropriate for asylum seekers, because of their specific life conditions. As they are distressed by the experience of flight from their countries, housed in reception centres and shelter houses, where social and humanitarian workers mediate with services, and not allowed to work, they rarely interact with the Italian society and have difficulty in identifying their own educational needs.

All research participants reported a positive impact of IL $2 S$ on their teaching, with obvious differences due to experience, competence, self-confidence and teaching approaches.

The coherence with the Common European Framework was pointed out as a positive feature, as research participants are used to turning to CEFR for course, material and test design.

I have structured the course plans using the descriptors of the Syllabus, and I have found myself in the same architecture of the Common European Framework.

Research participants stressed, as further advantage point, the relations between literacy programmes and CEFR. In particular, they appreciated the articulation between primary literacy teaching and language teaching in the communicative perspective. This approach - already adopted by some teachers - urges to overcome the view of literacy acquisition as a process leading to master mere technical skills. 
Beyond complementing CEFR for teaching literacy, IL $2 S$ presents the additional advantage of organizing in a single book pieces of information, which before were widespread across different sources. However, one participant complained: «The consultation is not always easy; sometimes we lose a bit of heart. It takes expertise to consult it».

There is little visibility, even graphically, of the C tables (Literacy Objectives); they are not incisive, it is as if they were just thrown in, while for me they were my bread and butter. Maybe they should have been presented graphically in a different way.

Regarding the efficacy of Syllabus as an instrument for planning, the can do descriptors and the language contents were useful to define the stages of the development both of communicative language competence and literacy.

Syllabus is functional and intuitive and actually helps to organize planning and specific works. In my opinion, establishing a context with "appropriate" goals helps teachers who are not used to groups of semi-literate learners not to lose hope, to deal with one thing at a time, to go on slowly, and to be systematic.

A clearer organization, a more systematic organization of the learning objectives, a more realistic pace in the presentation of the contents - sometimes slower, sometimes faster than the usual one - were indicated as positive outcomes of the experimentation, especially with the illiterate and semi-literate groups. The experimentation led to a more accurate course planning:

I had never planned so long-term, because I always planned for short times, also picking up clues from what happened in the class.

\section{CONCLUSIONS}

The results of the validation procedure show that IL $2 S$ has a positive impact on the quality of teaching. It helps the teachers better understand the educational needs of learners. It provides them with practical suggestions about the content of teaching and its progression according to the learners' needs, the aim of the course, and the teaching setting.

Although IL2S focuses on the Italian language, we propose it as a contribution to a European L2 and literacy syllabus. Migration has both local and international dimensions, as the constantly changing routes and forms of people's movements show. We are convinced that ongoing revision of the CEFR to make it more suitable to language learning and teaching in migration contexts is a European endeavour, to which experiences from each country can contribute.

This syllabus must be able to give an account of the diversity of learning profiles, and of the specificity of literacy in L2. The language and literacy learning paths are strongly connected and interlinked, but they do not overlap. Instead of "progression", "progressions" are to be described. The syllabus must also consider the vast array of 
communicative situations and language needs that migrants meet across a multilingual Europe, including individual as well as social and educational conditions.

\section{REFERENCES}

Beacco J-C. (2008), The role of languages in policies for the integration of adult migrants. Concept Paper prepared for the Seminar «The Linguistic integration of adult migrants», Strasbourg, 26-27 June 2008, Council of Europe, Strasbourg.

Beacco J-C., De Ferrari M., Lhote G., Christine Tagliante (2005), Niveau A1.1 pour le français: Référentiel et certification (DILF) pour les premiers acquis en français, Didier, Paris.

Beroepsoderwijs en volwasseneneducatie (2008), Raamwerk Alfabetisering NT2, Cito, Arnhem.

Borri A., Minuz F., Rocca L., Sola C. (2014), Italiano L2 in contesti migratori. Sillabo e descrittori dall'alfabetizzazione all'A1, Loescher, Torino.

Bundesamt für Migration und Flüchtlinge (2009), Konzept für einen bundesweiten Integrationskurs mit Alphabetisierung, Bundesamt für Migration und Flüchtlinge, Nürnberg.

Council of Europe (2001), Common European Framework of Reference for Languages: Learning, teaching, assessment, Cambridge University Press, Cambridge.

Finnish National Board of Education (2012), National core curriculum for literacy training for adult migrants, Finnish National Board of Education, Helsinki.

Fritz T., Faistauer R., Ritter M., Hribesch A. (2006), Rabmencurriculum. Deutsch als Zweitsprache und Alphabetisierung, Universität Wien - Institut für Weiterbildung, Verband Wiener Volksbildung - AlfaZentrum für MigrantInnen der Volkshochschule Ottakring, Wien.

Markov S., Scheithauer C., Schramm K. (2015), Lernberatung für Teilnehmende in DaZAlphabetisierungskursen, Waxmann, Münster.

Minuz F. (2005), Italiano L2 e alfabetizzazione in età adulta, Carocci, Roma.

Minuz F., Borri A., Rocca L. (2016), Progettare percorsi dall'alfabetizzazione all'A1, Loescher, Torino.

Rocca L. (2009). Percorsi per la certificazione linguistica in contesti di immigrazione. Definizione dell'utenza. Specificarioni degli esami. Prospettive future, Guerra, Perugia.

Spinelli B., Parizzi F. (2010), Profilo della lingua italiana. Livelli di riferimento del QCER A1, A2, B1, B2, La Nuova Italia, Firenze.

Tarone E., Bigelow M. (2005), "Impact of literacy on oral language processing: Implications for second language acquisition research", in Annual Review of Applied Linguistics, 25, pp. 77-97. 